NOWA KODYFIKACJA PRAWA KARNEGO Tom LX

NEW CRIMINAL LAW CODIFICATION

AUWr No 4039

Wrocław 2021

https://doi.org/10.19195/2084-5065.60.8

\title{
The role of paper embedded security features in effective border control
}

\author{
SALEH MANSOUR \\ ORCID: 0000-0002-4111-4704 \\ Faculty of Criminology, Lebanese University, Beirut, Lebanon \\ SHIPRA ROHATGI \\ ORCID: 0000-0003-0532-9908 \\ Faculty of Forensic Sciences, Amity University, Noida, India
}

\begin{abstract}
Security documents are crucial types of documents, whose authenticity is genuine and cannot be counterfeited. For different types of security documents, a security paper is used, which possesses the property of being impenetrable to mileage, high temperature with unequivocal GSM, haziness, and thickness. This makes it sensible for merging the security features that make it different from normal paper. The commonly used substrate for any security document manufacturing is either plastic or paper. The process of manufacturing a security document begins with paper manufacturing by mechanical and chemical processing of wood pulp, and the security elements are incorporated in the further processing stages. The raw material used is mainly pure cotton fiber-based cellulose mixed with titanium oxide. The major security features include security threads, fibers, planchettes, and water marks which play a critical role in keeping up the uprightness of the security record for a fruitful edge control. Identity theft as well as deceitful utilization of personality and travel reports are the fundamental dangers confronting the control at international borders, while checking the legitimacy of the travelers' character records assumes an essential job in guaranteeing the effectiveness of fringe control.
\end{abstract}

Keywords: substrate, security paper, watermark, fibers, planchettes, hi-lights, security thread

Nowa Kodyfikacja Prawa Karnego 60, 2021

(C) for this edition by CNS 


\section{Introduction}

The substrate is an underlying layer or substance over which a reaction takes place, an organism grows. Paper serves as a substrate for the evolution of various document types such as wills, deeds, currency notes, bank checks, stamps, as well as identity documents, passports, visas, driving licenses, etc. The role of paper used in the manufacturing of security documents is very significant in terms of their admissibility when converted into a precious and authenticated document. The security documents are generally produced on two major types of substrates: paper and plastic. The raw material used for security documents is mainly pure cotton fiber-based cellulose mixed with titanium oxide and various security features are embedded into it as per the requirement of security document production. The security papers possess the property of being resistant to wear and tear, high temperature with specific GSM, opacity, and thickness, making it suitable for incorporating the security features. ${ }^{1}$

Those features are the everlasting, capable, and sincere guards of document value - their role is not restricted to protecting private rights, they also protect borders by preventing illegal entry of criminals and terrorist imposters as well as supporting border guards with effective ways to perform their duties.

To put it differently, identity theft and fraudulent use of identity and travel documents are the main threats facing border control management systems, while verifying the authenticity of the identity documents of passengers plays a crucial role in assuring the efficiency of border control management. Most threats against identity and travel documents are represented by photo substitution, modifying alpha-numeric data, passport biodata page substitution, visa pages substitution, and so on. Accordingly, security features in identity and travel paper documents are of four main types: paper embedded features, printing techniques used in the docu-

1 C.M. Deviterne-Lapeyre, "Interpol review of questioned documents 2016-2019", Forensic Science International: Synergy 2, 2020, pp. 429-441; Fabriano Security, "Banknote and security papers", http://www.fabrianosecurity.com/en/15/banknote_\&_security_papers (accessed: 30.06.2020); M.B. Shaw, G.W. Bicking, Research on the production of currency paper in the bureau of standards experimental paper mill, Department of Commerce Bureau of Standards, Washington, D.C. 1926. 
ment manufacturing process and personalization process, additional security features such as optical variable devices (kinegram and hologram), and data saved in an RFID electronic chip for e-passports. However, the most effective security feature is one that is easy to check and at the same time hard to imitate. This makes paper embedded security features in the forefront, knowing that the major forging and counterfeiting threats against identity and travel documents are focused on personalizing additive photos, identity, and other alpha-numerical information which is added to the paper and not embedded inside it.

In addition to paper substrate, polycarbonate, Teslin, polymer, and other types of substrates are used in value documents; despite that, the paper is the oldest type, still widely used all over the world for almost all kinds of value documents. This article is going to demonstrate the main paper embedded security features, starting from paper ingredients, watermarks, security threads, fibers, planchettes, and hi-lights, whose level of technological advancement is very high in order to ameliorate their strength and make any attacks more and more difficult.

\section{Paper production}

Pulps are produced from a diversity of cellulose-containing raw materials, such as hard and softwood as well as non-wood sources, including hemp, jute, flax, sisal, and cotton. ${ }^{2}$ Moreover, compared to all kinds of natural fibers, cotton fiber has the highest cellulose content in nature - it constitutes $95-97 \%$ of its ingredients. Besides, cotton-based raw materials have a rich variety of excellent properties in physical and optical aspects. Firstly, the fiber length of cotton raw material is between $20-30 \mathrm{~mm}$ with diameter around 20 micrometers, ${ }^{3}$ whereas softwood's fiber length is $3 \mathrm{~mm}$ and its diameter about 20 to 35 micrometers. ${ }^{4}$ Secondly, cotton

2 Z. Liu, H. Wang, L. Hui, "Pulping and papermaking of non-wood fibers", [in:] Pulp and paper processing, ed. S.N. Kazi, 2018, IntechOpen, https://www.intechopen.com/ chapters/62223 (accessed: 10.07.2020).

3 Ibid.

4 Mini-encyclopedia of papermaking wet-end chemistry: Additives and ingredients, their composition, functions, strategies for use, https://projects.ncsu.edu/project/hubbepaperchem/FIBR.htm (accessed: 18.07.2020). 
fiber has the merits of excellent flexibility, good tenacity, elasticity and absorptivity, high strength and opaqueness, robust resistance to dilute acids and alkalis, and can be stored for a long time. ${ }^{5}$ This gives an advantage to the cotton-based paper that is stronger than the first, durable, and will not turn yellow with time. All these features are extremely suitable for manufacturing security document papers such as passports and banknotes, which are used repeatedly and frequently for a long period. Conversely, wood-based paper has less flexibility, less elasticity, less durability than cotton-based paper, and will turn yellow with time.

The cotton fiber has even more merits:

- the polymerization degree (the number of repeat units linked together to form the cellulose polymer) is between 9000 and 15000 (wood fiber: 600-1 500);

- crystallinity (which indicates that the fiber molecules are closely packed and parallel to one another) is about $73 \%$ (wood fiber: $35 \%$ );

- high level of hygroscopicity thanks to thinner fiber;

- good bendability that makes it hard to break;

- the best heat-resisting property among all-natural fibers - it remains flexible even at very low temperature and decomposed gradually when under long exposure to dry heat (above $300^{\circ} \mathrm{F}-149^{\circ} \mathrm{C}$ );

- the high temperature required for the beating process to manufacture the paper;

- good mechanical properties such as friction and cohesion due to its natural bending. 6

\section{Wood paper manufacturing process}

It aims at preparing a pulp of cellulose fiber to produce paper. As for wood-based raw materials, the manufacturing process begins from wood logs, which are placed in a rotating drum to remove the bark, then moves

5 CNBM International Pulp \& Paper, “Cotton pulp making”, http://www.paperpulpingmachine.com/applications/cotton-pulp-making/ (accessed: 19.07.2020); Z. Liu, H. Wang, L. Hui, op. cit.

6 Cotton Incorporated, “Cotton morphology and chemistry”, https://www.cottoninc. com/quality-products/nonwovens/cotton-fiber-tech-guide/cotton-morphology-and-chemistry/ (accessed: 19.07.2020); CNBM International Pulp \& Paper, op. cit. 
to the chipping process to select a uniform chip size. For pulp formation, two main methods are used:

- chemical process - a digester with chemicals is used to cook wood chips aiming at removing lignin and fritting the wood chips into fibers, the majority of chemical wood pulp production in the world used to digest the wood chips are using alkaline kraft or sulphate process, by using caustic soda and sodium sulphate (around 80\%), and the other method is represented by the sulphite pulping process (around 10\%);

- mechanical process - it uses mechanical forces to separate fibers from groundwood, by rotating either drums, grinders, or refiners. However, wood chips are pre-softened by heating or chemical treatment when needed.

The bleaching stage aims at adding certain characteristics to the paper: strength, stability, cleanness, and brightness. All other embedded security features such as fibers, planchettes, hi-lites, and security threads are added to the pulp at this stage, before either being transferred for drying to the paper making pulp mill in an integrated process, or being pressed and dried in a wet state. Additionally, subsequent treatment and coating might be done to get the properties favorable to the purpose the papers will be used for. ${ }^{7}$

However, the manufacturing technology used for paper production can enhance and improve the embedded security features in the paper product, including anti-bacterial, anti-soiling, and additive chemical properties:

- antibacterial paper: is manufactured in response to banknotes being circulated through the hands of an uncountable number of people. This feature plays a preventive role against different types of bacteria to be shifted through the banknotes;

- anti-soiling paper: represented by adding a coat to the paper to increase its resistance to soil;

- paper intended for ink-jet personalization: for improving the quality and durability of the ink-jet personalization process by unique coating materials;

7 European Bank for Reconstruction and Development, Sub-sectoral environmental and social guideline: Pulp and paper, 2014. https://www.ebrd.com/documents/environment/env-emanual-manufacture-of-paper-and-paper-products.pdf(accessed: 10.07.2020). 
- the semi-synthetic paper: aimed to improve the quality of highly secured paper by adding specific organoleptic properties;

- Laser Engravable Anti-Counterfeiting Paper (LEAP®): a unique highly secured characteristic, represented by adding special components and coating solution to the pulp which allow applying personalized data by all available techniques, including laser engraving, to produce a clear, legible image without the need of additional laminate to the paper, and to draw an engraving trail on the paper surface as well as within the paper pulp, strengthening an image viewed through transmitting light. The records can be detected by touch; ${ }^{8}$

- chemically secured paper: aimed to protect imprinted data in the document from forging attacks and any unauthorized data-changing attempts using chemical reagents or solvents.

\section{Cotton paper manufacturing process}

The commonly used cotton pulp making process is cotton linter alkaline pulping, which includes five steps:

- material preparation of cotton linter to obtain a treated cotton linter with impurity rate between $1 \%$ and $3 \%$;

- pulp cooking by cyclone separator and then adding some additives pulp digester;

- pulp washing by beating to increase the hydration degree and washing the pulp using various equipment, including a vacuum drum washer, a twin roll press, a single screw press, or others;

- pulp screening and degritting for removing various impurities and to separate the fine pulp and coarse screenings;

- pulp bleaching process that aims at meeting the specific paper characteristic requirements, and for this reason bleaching circumstances, conditions, equipment, and bleaching agent are strictly controlled. ${ }^{9}$

8 Polish Security Printing Works (PWPW), "Security features", https://www.pwpw. $\mathrm{pl} / \mathrm{en} /$ Competencies/Security_features.html\#elementy_zabezpieczajace_w_papierze (accessed: 18.07.2020).

9 CNBM International Pulp \& Paper, op. cit. 
The produced cotton-based paper is characterized by strength, durability, flexibility, elasticity, finesse, softness, and high opaqueness which are not found all together in any other kind of paper.

\section{Watermark}

The two main paper machine production types are Fourdrinier and cylinder mould machines. The first is used to produce a continuous web of paper, whereas the second is used for single sheet production. ${ }^{10}$

The watermark in papers is a method for securing documents, its main concept is changing density variation of paper thickness. A watermark formed during the production process by exerting pressure of special motif on the wet paper pulp to produce thick and thin areas, hence, fibers are distributed within the paper according to the design of the watermark motif, where darker areas contain a higher density of fibers and lighter areas contain a lower density of fibers, ${ }^{11}$ and hence no additives are added to the paper. ${ }^{12}$ Correspondingly, the authentic watermark comprises a refined variation in tone and both lighter and darker areas. ${ }^{13}$

However, checking the authenticity of a watermark needs transmitted light (holding it to a light source or shining a torchlight through the paper) which shows different shades of lightness and darkness to perform a special motif, such as an image, numbers, shapes, or a specific design, and could be distributed in the center of the page, in various locations, in a specific area, or covering the entire area of the page. ${ }^{14}$ Additionally, the watermark represents one of the most distinctive, feasible, and inimit-

10 H.A.A. Al Faleh Al Hiary, "Paper-based watermark extraction with image processing”, doctoral thesis, July 2008, http://etheses.whiterose.ac.uk/1355/1/hazem.pdf.

11 D. Ellen, S. Day, C. Davies, Scientific examination of documents: Methods and techniques, Boca Raton, FL 2018.

12 P.K. Chahal, J. Kaur, P. Singh, "Digital watermarking on bank note", International Journal of Soft Computing and Engineering (IJSCE) 3, 2014, no. 6.

13 Paper Money Grading (PMG), "Substrate feature: The watermark", 20.08.2013, https://www.pmgnotes.com/news/article/3525/Substrate-Feature-The-Watermark/ (accessed: 5.07.2020).

14 P.K. Chahal, J. Kaur, P. Singh, op. cit. 
able security elements - it is simultaneously very easy to check and very hard to reproduce. ${ }^{15}$

Such a production process makes the watermark unreproducible by the counterfeiters and hence a strong security feature protecting value documents from illegal attacks in the form of forging and counterfeiting.

There are many kinds of watermarks:

- linear watermark: wire and single-tone watermark, represented by areas either lighter or darker than the whole paper;

- dual-tone watermark: when areas both lighter and darker from the whole paper are found together;

- shadow watermark: or multi-tone watermark, represented by gradual transitions of lightness and darkness between various areas embedded in the same paper leaf, or a light and shade feature. The Bank of France was the first one issuing multi-tone watermarks in 1829 , followed by the Bank of England in 1855, when first shaded watermarks in banknotes were issued; ${ }^{16}$

- combined watermarks: a mixture of linear and shadow watermarks in one paper leaf, ${ }^{17}$ this type of watermarks started to appear in the $1990 \mathrm{~s} ;{ }^{18}$

- pixel watermark: comprised of a regular or irregular matrix of dark-colored dots on a light background, it is tremendously difficult for forgers to copy;

- high-light watermark: are produced during the paper manufacturing process by eliminating the fibers to very low levels, which allows creating very light areas, aiming at increasing the visibility of a specific design motif (Figure 11) when examined with transmitted light; they appear as more prominent heightened areas within the other types of combined watermark (Figures 1, 3, 4); ${ }^{19}$

15 Radecepapir Nova, "The watermark: The oldest and most reliable paper protection element", https://www.radecepapir.si/the-watermark-the-oldest-and-most-reliablepaper-protection-element/ (accessed: 5.07.2020).

16 H. de Heij, "Banknote design for retailers and public", DNB Occasional Studies 8, 2010, no. 4, https:/www.dnb.nl/binaries/OS0804_tcm46-244782.pdf.

17 H.A.A. Al Faleh Al Hiary, op. cit.

18 H. de Heij, op. cit.

19 Louisenthal, https://www.louisenthal.com. 
- digital watermark: a term was first used by Komatsu and Tominaga in 1988 (Figure 2). ${ }^{20}$

There are four main types of watermarks according to the position in the paper:

- general: the motif is repeated in consistent intervals all over a document page (Figures 5, 6, 7);

- local: the motif is repeated in a certain place on a document page (Figure 4); ${ }^{21}$

- cornerstone: located at the corners of the page (Figure 8);

- edgestone: located at the edges of the page.

Moreover, lightness and darkness of watermark areas are described concerning the general paper tone:

- single-tone: contains darker or lighter areas of a special motif in comparison with the general paper tone;

- dual-tone: contains darker and lighter areas of a special motif in comparison with the general paper tone;

- multi-tone: contains gradual transformation between darker and lighter areas to perform a shadow image or a specific motif. ${ }^{22}$

Furthermore, it is very rare to find a paper security document like banknotes and passports, without watermark, which indicates the high significance aspect of the watermark in protecting value documents. However, despite the tremendous technological development of document security features, watermarks are still the main recommended feature to be embedded in all the world's major banknotes ${ }^{23}$ to ensure high performance of protection against counterfeiting.

As long as security papers are made from cotton, which consists of cellulose without bleaching additives, they are optically dead, which im-

20 I.J. Cox, M.L. Miller, J.A. Bloom, Digital watermarking, San Francisco-London 2002.

21 Arjowiggins Security Papers, "Security features", https://securitypapers.arjowiggins.com/security/ (accessed: 12.07.2020).

22 Ibid.

23 P.K. Chahal, J. Kaur, P. Singh, op. cit 
plies that they absorb UV light and do not shine under it - in other words, the real watermark should never react under UV light. ${ }^{24}$

There are two main methods of watermark production for pacing a motif: a graphic, a pattern, a number, or an image into the fibers of the paper.

\section{Dandy roll watermark}

The first dandy roll was invented and used for watermark production in 1282 (Fabriano, Italy). ${ }^{25}$ In 1826, John Marshall introduced a developed dandy roll machine which makes the watermark production process easier. ${ }^{26}$

During the paper manufacturing process, the initial step starts with paper pulp, which consists of around 99\% water. The pulp is then transferred onto the wire from the headbox; during this process it loses $5-10 \%$ of its water. The paper web passes under a cylinder called a dandy roll, covered by embossed material with a special motif design (Figure 12). ${ }^{27}$

The roller is similar to a window screen and stronger than it - to depict the motif or special design, the screen is made of intersecting lines of laid wires and upon those chain wires, when the paper pulp moves in the passage within the web, the dandy roll trundles along with it when it is still fairly wet to create a faded impression on the paper pulp. However, the motif still fades until the paper dries. ${ }^{28}$

24 Home Office UK, National Document Fraud Unit, Guidance on examining identity documents, 2016, https://assets.publishing.service.gov.uk/government/uploads/system/ uploads/attachment_data/file/869551/Guidance_on_examining_identity_documents_v._ February_2020.pdf.pdf (accessed: 19.07.2020).

25 P.B. Meggs, A history of graphic design, Chichester 1998, p. 58; H. de Heij, op. cit.

26 P.K. Chahal, J. Kaur, P. Singh, op. cit.; Paper Money Grading (PMG), op. cit.

27 Special techniques: Embellishments for paper, http://www.csus.edu/indiv/c/cunninghamk/links/lectures/5special_process.pdf (accessed: 5.07.2020).

28 Paper Money Grading (PMG), op. cit.; European patent specification, Watermark formation element, International publication number: wo 2016/075442 (19.05.2016 gazette 2016/20), 26.09.2018 bulletin 2018/39, https://patents.google.com/patent/US5766416A/en (accessed: 5.07.2020); M.B. Shaw, G.W. Bicking, op. cit. 


\section{Cylinder mould watermark}

In contrast with the dandy roll, the Cylinder Mould roll contains different areas of relief conferring the special motif or design, in form of a sieve to create a three-dimensional image when rolled onto the wet paper pulp. Created in 1848, it is highly effective and most commonly used in the watermarking paper nowadays. ${ }^{29}$ An embossed watermark on paper, that is imprinted in the sieve itself, is possibly produced under the development of this process, hence, one, two, or multi-tonal depths of grayscale effects on paper pulp could be created with the help of the relief of the sieve, ${ }^{30}$ to produce clearer and more detailed watermark than the dandy roll method (Figure 10). ${ }^{31}$

There are many other uses for the watermark, it can be used for paper dating in forensic investigation, for example, the case of "Shakespearean quartos published by Thomas Pavier," when a false date given for all of them was 1619, whereas investigating these watermarks in 1908 by Sir Walter Greg provided the investigation with the proof that those quartos were published at three different dates, 1600, 1608, and 1619. ${ }^{32}$

On the other hand, significant investigative information about the size and quality of the original paper could be revealed from the size and orientation of the watermark, which leads to determining the usage of the paper, since the definite size of the paper was used for a specific purpose. By the same token, date and shape detail determination of paper watermark could be used to investigate forgeries of different kinds of value documents like wills, patents, bills, dons, contracts, and so on. ${ }^{33}$

\section{Security thread}

A thin metallic or polymer strip embedded into the paper web during the paper manufacturing process, integrated or woven and intertwined inside the paper. Additional security features can be added to the security

29 Paper Money Grading (PMG), op. cit.

30 Radecepapir Nova, op. cit.

31 P.K. Chahal, J. Kaur, P. Singh, op. cit.

32 H.A.A. Al Faleh Al Hiary, op. cit.

33 Ibid. 
thread, such as imprinted invisible UV ink on security threads, motion effect, negative and/or microprinting, etc.

Moreover, the incorporation methods of the security thread within the paper have many different forms: completely embedded the paper (latent), woven in rectangular visible shapes, or patent in the naked eye.

1. The latent security thread is entirely located in the paper and can be seen in transmitted light only (Figures 14 A, 14 B, 20).

2. Woven or diving security thread visible on the paper surface as rectangles which form a dotted line on the surface and a solid line when viewed in transmitted light (Figures 14 C, 14 D, 17, 18, 21);

3 . Patent of figured security thread appears partially on the paper surface as a figured window and as a solid strip when viewed against the light (Figures 14 E, 14 F, 20).

Furthermore, a large variety of materials are used to perform additional security levels of threads, like metalized based threads without texts, metalized with microtext applied by demetalization (Figures 13 and 15), semi-transparent with texts (Figure 16), holographic (Figures 18 and 21), color-changing effect (Figure 17), luminescent under UV light (Figure 21), magnetic properties; with the "floating" motion image (Figure 21), optically variable effect "scate" where the image disappears from the security thread at a certain angle of view and leaves iridescent tints of the hologram (Figure 22), optically variable effect "chameleon" where the images applied on the security thread look positive under reflected light and negative in transmitted light (Figure 23), and kinetic mobile effect represented by shifting of certain images relative to each other by changing the angle of view.

Even though security thread by itself is classified as a first-level security feature, the additional embedded features such as microtext and UV glowing ink upgrade it to the second level, whereas higher ranking additional features like complicated patterns and designs, as well as materials interaction make the security thread add a very strong and highly effective security protection feature to the paper substrate. ${ }^{34}$

34 J. Chambers et al., "Currency security and forensics: A survey", Multimedia Tools and Applications 74, 2015, no. 11, pp. 4013-4043. 


\section{Fibers}

Security fibers are synthetic materials added to the pulp during the paper production process. They are randomly scattered all over the paper or concentrated in a certain area. ${ }^{35}$ These fibers are of different types, visible to the naked eye (colored), invisible (colorless), monochrome colored (Figure 24), two-colored, and multi-colored with various fragments of different colors. Moreover, the fluorescence feature of these fibers under UV and/or IR lights might be added (Figures 25 and 26). Furthermore, the most known fiber shape is the simple monotone form with a persistent cross-section; however, a complex multitone width variation of fibers is a specified high-security feature (Figure 27).

Accordingly, when this paper is held up against a light source, these fibers glow and show different colors. Apart from other features, these security fibers are also imitated in some high-profile forgeries and counterfeiting. To the normal public, these features are not visible, but they can easily be examined by forensic tools and technologies. ${ }^{36}$ They do not affect the physical and chemical constituents and characteristics of the paper and yet can readily be used to reduce the risks of counterfeiting. These fibers are both fluorescent and colored (Figure 26). The level of security in documents is highly increased when these security papers are administered with fibers. In addition to other security features, in further stages, laser and mechanical perforation are done to enhance the security. ${ }^{37}$

Currency paper in the U.S. has red-blue fibers that are added in the paper slurry and get dissipated all over in the paper. Visually they can be observed but a close examination and good light is required to detect and inspect them. They can get away with simple visual inspection but a careful examination deters counterfeiting. ${ }^{38}$ Security optic fibers are dissipat-

35 Regula Forensics, "Glossary of documents", https://regulaforensics.com/en/knowledge-hub/glossary-documents/ (accessed: 12.07.2020).

36 J. Chambers et al., op. cit.

37 A.B. Centeno et al., Identity document and banknote security forensics: A survey, 2019, https://arxiv.org/pdf/1910.08993.pdf.

38 National Research Council, Counterfeit deterrent features for the next-generation currency design, Washington, D.C. 1993. 
ed on both sides of the currency note and when it is observed through UV trans-illuminator, they show different colors. ${ }^{39}$

Counterfeiters also simulate these fibers, but while doing so the random pattern of the fibers are not achieved and gives a red flag while examining a suspicious piece of evidence. These specific fibers have a different reaction to UV light which helps to ascertain the authenticity of the substrate. ${ }^{40}$

\section{Planchettes}

Planchettes are tiny pieces of $1-4 \mathrm{~mm}$ size, rounded or different sided shapes, are added to the pulp during the paper production process, hence they are incorporated into the main paper as one of the security features of special security documents, ${ }^{41}$ and distributed randomly into the whole paper sheet areas or in certain locations. As we may know, in forensic document examination, paper and fiber comparisons are done, planchettes are also examined as per the need.

To explain in a better way, planchettes are disc-type structures and are optically variable in nature, showing different effects and color change. These properties enable them to serve as security features. ${ }^{42}$ They are usually made up of cellulose and round around $1.6 \mathrm{~mm}$ and are of different lengths and colors. They are put in paper pulp and appear randomly. Planchettes are of different types; they are visible in daylight or show fluorescence or phosphorescence under ultra-violet light. ${ }^{43}$ They are disseminated at the time of paper production and they appear as tiny particles in the layer of paper. Planchettes have assertive characteristics that remain intact even after they are scattered in the paper. They are distinctive and can very easily be examined under the microscope. Usually, they are made

39 A. Anjali et al., "Comparison of various security features of genuine, scanned and photocopied Indian currency note of the denomination 2000", Journal of Forensic Science \& Criminology 5, 2017, no. 3, p. 305.

40 Thales Group, High-security printing for passport: The 2021 expert's guide, https://www.thalesgroup.com/en/markets/digital-identity-and-security/government/passport/security-printing (accessed: 7.07.2020).

41 Regula Forensics, op. cit.

42 Materials analysis in forensic science, ed. M.M. Houck, Amsterdam 2016.

43 Regula Forensics, op. cit. 
of paper and sometimes can be metallic, polymer, and even transparent. Apart from their UV activity, planchettes can also exhibit a change in color if the material which they are made of is iridescent in nature. ${ }^{44}$ These minute discs remain embedded over the paper and they become visible when they are held against a light source. For additional security, they have micro-printing on them. ${ }^{45}$

\section{UV-Fluorescent Hi-Lites}

Micro-particles of different sizes and various colors, or colorless, added to the pulp during the paper production process. In a similar manner to fibers and planchettes, the Hi-Lites are distributed randomly within the whole paper and fluoresce when exposed to UV light (Figure 32). ${ }^{46}$

\section{Conclusion}

The aim of paper utilized in the assembling of security archives is exceptionally critical in terms of their acceptability. Paper serves as a substrate for the advancement of different sorts of security documents. The crude material utilized for the equivalent is for the most part unadulterated cotton fiber-based cellulose blended in with titanium oxide where cotton fiber has the benefits of phenomenal adaptability, great industriousness, versatility, high quality, obscurity, vigorous protection from weaken acids and antacids. ${ }^{47}$ Giving a favorable position to the cotton-based paper is more grounded than the principal, sturdy, of higher caliber, and will not turn yellow with time. The security papers have the property of being impervious to mileage, high temperature with explicit GSM, murkiness, and thickness, making it reasonable for joining the security highlights. ${ }^{48}$ Iden-

44 Security Paper Mill (SPM), "Security features in paper structure", http://spm. cz/en/products/security_papers/security_features_in_paper_structure.html (accessed: 7.07.2020).

45 J. Chambers et al., op. cit.

46 Regula Forensics, op. cit.

47 CNBM International Pulp \& Paper, op. cit.; Z. Liu, H. Wang, L. Hui, op. cit.

48 C.M. Deviterne-Lapeyre, op. cit.; Fabriano Security, op. cit.; M.B. Shaw, G.W. Bicking, op. cit. 
tity theft and deceitful utilization of character and travel reports are the primary dangers confronting outskirt border control frameworks, while confirming the genuineness of the personality archives of travelers assumes a urgent job in guaranteeing the proficiency of fringe control the executives. Most dangers against character and travel archives regard photograph replacement, changing alpha-numeric information, identification bio-data page replacement, visa pages replacement, expansion sticker replacement, etc. ${ }^{49}$ The watermark in papers is a technique for checking records' validity, the primary idea of watermarks is changing thickness variety of paper. A watermark is delivered during the creation procedure by applying weight of unique theme design on the wet paper mash to create good and bad areas; hence, filaments are dispersed inside the paper as per the plan of the watermark theme, where darker regions contain a higher thickness of strands, and lighter regions contain a lower thickness of filaments. ${ }^{50}$ The two principle paper machine creation types are Fourdrinier and cylinder form machines: the first is utilized to deliver a ceaseless trap of paper, the second is utilized for single sheets creation. ${ }^{51}$ The security string was also discussed, which is a slim metallic or polymer strip implanted into the paper web during the paper producing process (Figures 20 and 21), incorporated or woven and interweaved inside the paper. Extra security highlights can be added to the security string, such as engraved imperceptible UV ink on security strings, movement impact, negative and additionally miniaturized scale printing, etc. Furthermore, the most realized fiber shape is the basic monotone structure with a constant cross-area; notwithstanding, a complex multitone width variety of strands is a predefined high-security include (Figure 27). Last but not least, planchettes are plate type structures and are optically variable in nature. These properties allow them to fill in as "security highlights." 52 They are typically comprised of cellulose and around $1.6 \mathrm{~mm}$, and are of various lengths and colors. All the security highlights play a significant role in keeping up the integrity of the security record for a successful outskirt control.

49 Ibid.

50 D. Ellen, S. Day, C. Davies, op. cit.

51 H.A.A. Al Faleh Al Hiary, Paper-based watermark extraction with image processing, doctoral thesis, July 2008, http:/etheses.whiterose.ac.uk/1355/1/hazem.pdf.

52 Materials analysis in forensic science. 


\section{Conflict of interest}

The authors declare that there is no conflict of interest regarding the publication of this paper.

\section{Appendix $^{53}$}

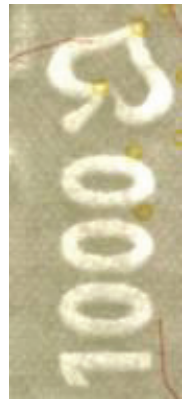

Figure 1. Highlight watermark, 1000 Czech Korun (2008)

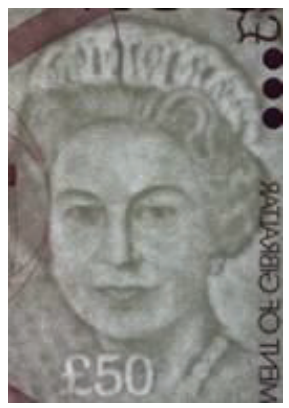

Figure 3. Combined (halftone and highlight), 50 Gibraltar Pounds (2010)

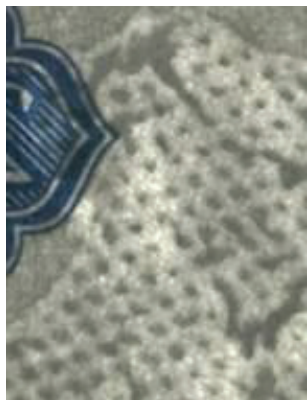

Figure 2. Pixel watermark, 1000 Kazakh Tenge (2011)

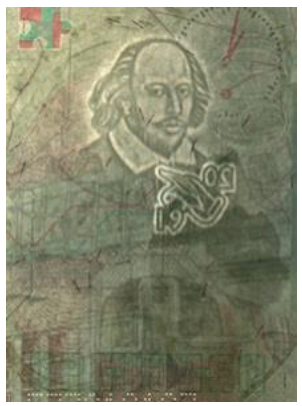

Figure 4. Great Britain, passport (2015), multitone shadow local watermark combined with electrotype watermark

53 For information about the sources of illustrations, see the list of figures below. Most illustrations were taken from Regula Forensics, "Glossary of documents", https://regulaforensics.com/en/knowledge-hub/glossary-documents/ (accessed: 7.07.2020); Regula forensics, "Glossary of banknotes", https://regulaforensics.com/en/knowledge-hub/glossary-banknotes/ (accessed: 12.07.2020). 


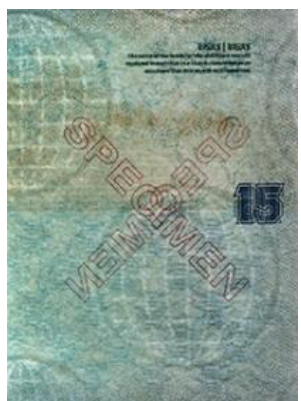

Figure 5. New Zealand, a travel document issued in 2016, dual-tone general watermark

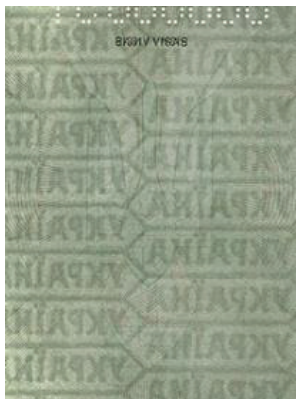

Figure 6. Ukraine, refugee's document for traveling abroad issued in 2017, single-tone watermark

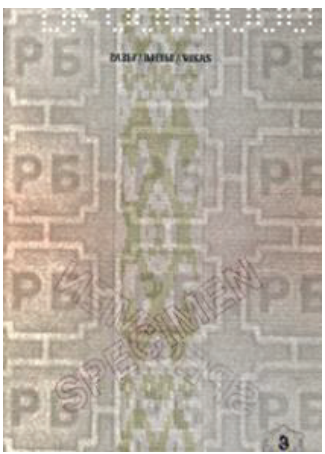

Figure 7. The Republic of Belarus, diplomatic passport issued in 2010, duotone watermark

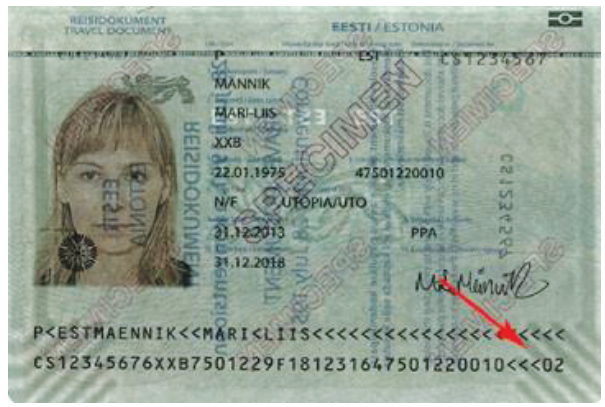

Figure 8. Estonia, a travel document issued in 2013, cornerstone watermark

Nowa Kodyfikacja Prawa Karnego 60, 2021

(C) for this edition by CNS 


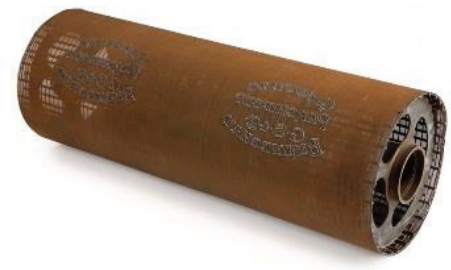

Figure 9. Dandy roll-made watermark

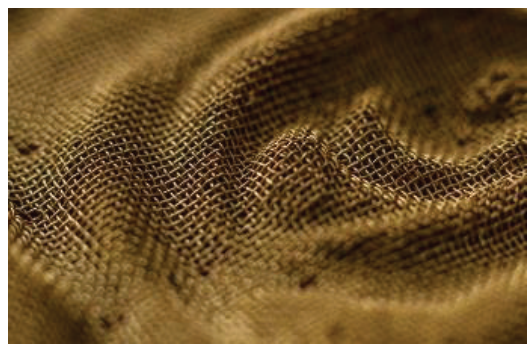

Figure 10. Mould-made watermark

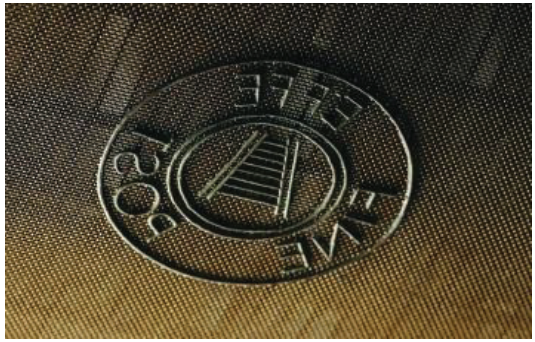

Figure 11. Electrotype made watermark

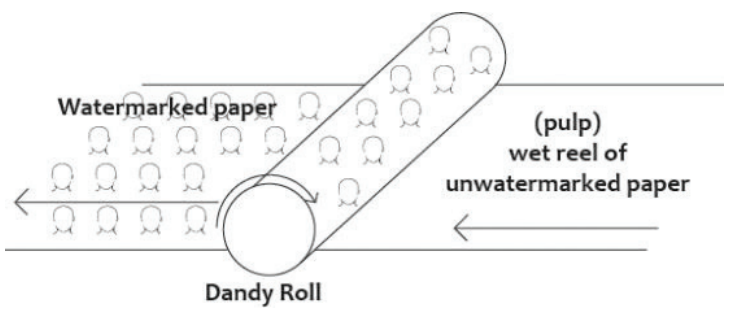

Figure 12. Dandy roll cylinder 


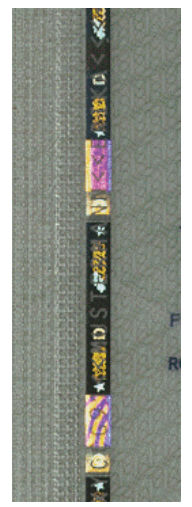

Figure 13. Metalized (machine-variable) security thread

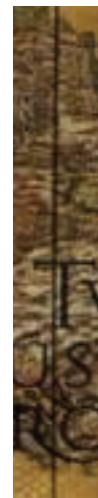

A

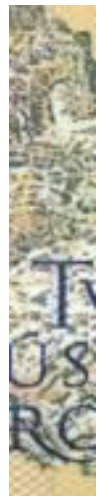

B

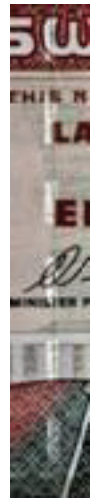

C

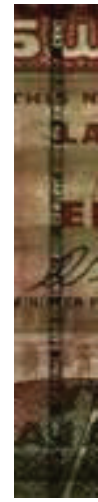

D

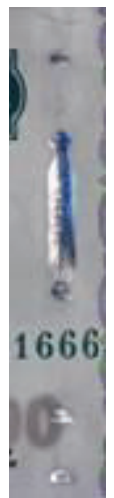

$\mathrm{E}$

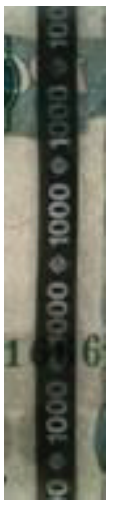

F

A, B - latent, 2000 Iceland Kronur (1986)

C, D - window, 50 Swaziland Emalangeni (1995)

E, F - figured, 1000 Russian Rubles (1997), modification of 2010

A, C, E-incident light

B, D, F - transmitted light

Figure 14. Three types of a security thread 


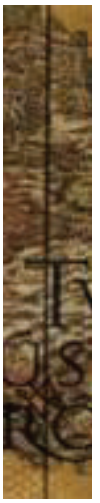

A

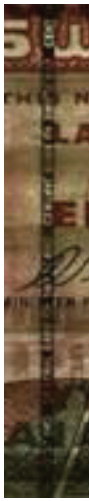

B
A - without texts, 2000 Iceland Kronur (1986)

B - with microtext, 50 Swaziland Emalangeni (1995)

Figure 15. Metalized security thread

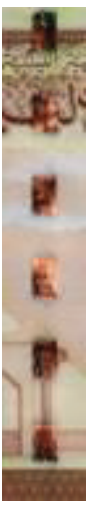

A

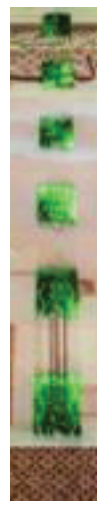

B

$$
\begin{aligned}
& \mathrm{A}-\text { at right angles } \\
& \mathrm{B}-\text { at an acute angle }
\end{aligned}
$$
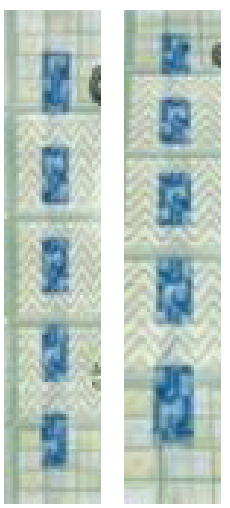

Figure 18. Motion effect, 100000 Lebanese Pounds (2011)
Figure 16. Semi-transparent with microtext, $10 \mathrm{UAE}$ Dirhams (1982)

Figure 17. Color changing, 50 Libyan Dinars (2008) 


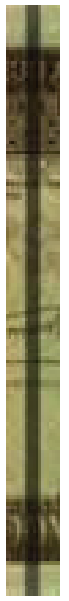

A

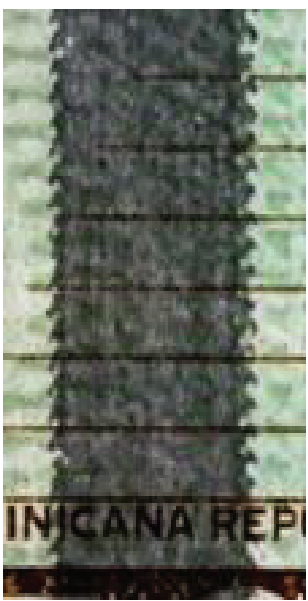

B

A - transmitted light

B - zoomed image in transmitted light

Figure 19. Dark thread without microtext, 20 Dominican Pesos (2009), in a polymer basis

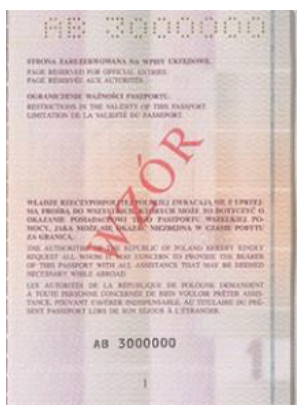

A

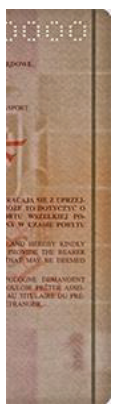

B

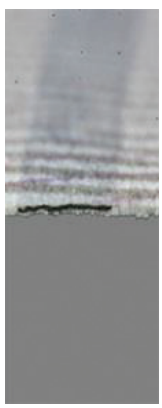

C

A - page

B, C - latent security thread, transmitted light

$\mathrm{C}$ - cross-section of a document page

Figure 20. Poland, passport issued in 2001 


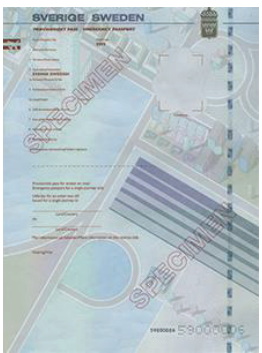

A

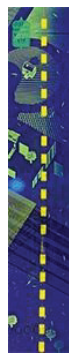

B
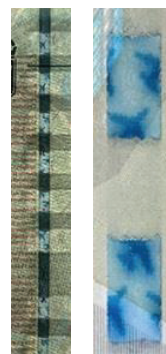

$\mathrm{C}$

$\mathrm{D}$

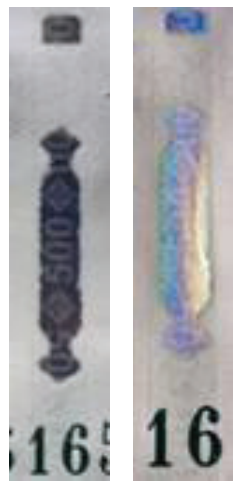

Figure 22. Optically variable effect "scate," 500 Russian Rubles (1997), modification (2010)

$\mathrm{C}$ - transmitted light

$\mathrm{D}$ - incident white light

The image of a plane moves when changing the angle of observation or illumination $\mathrm{B}$ and $\mathrm{D}$.

Figure 21. Sweden, emergency passport issued in 2011
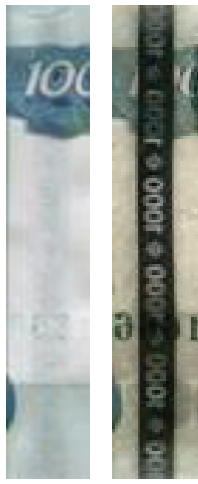

Figure 23. Optically variable effect "chameleon," 1000 Russian Rubles (1997), modification 2010

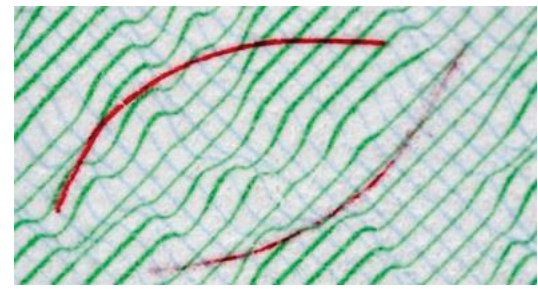

Figure 24. Azerbaijan, passport issued in 1998, visible simple monochrome fibers 

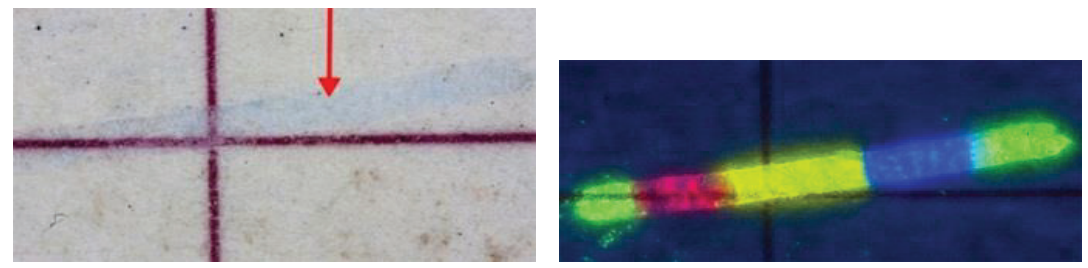

Figure 25. Great Britain, passport issued in 2010, invisible (colorless) simple fibers daylight, and the same under UV light
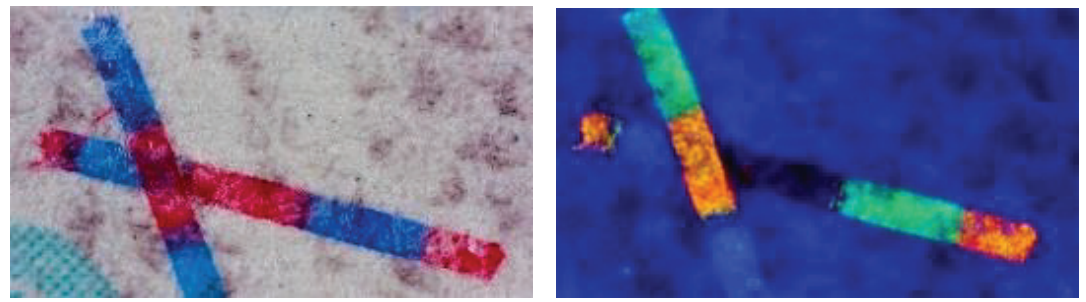

Figure 26. Great Britain, passport issued in 2010, visible (colorless) simple fibers daylight, and the same under UV light
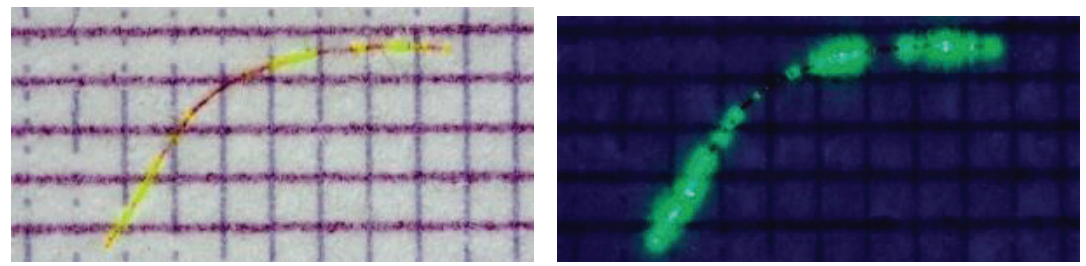

Figure 27. Russian Federation, passport issued in 2010, ZONA security fibers, two-colored with a variable cross-section daylight, and the same under UV light

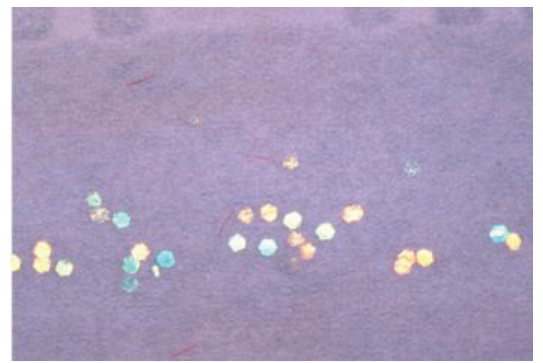

Figure 28. UV fluorescent multi-color planchettes, invisible under daylight

Nowa Kodyfikacja Prawa Karnego 60, 2021

(C) for this edition by CNS 


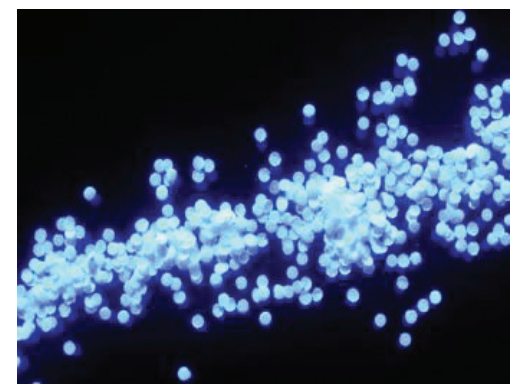

Figure 29. Planchettes, one color

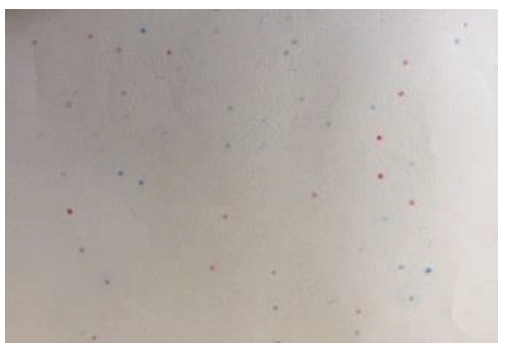

Figure 30. Visible multi-color planchettes

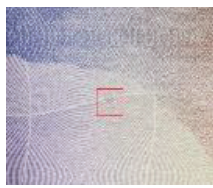

A

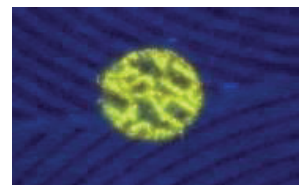

B

A - colorless planchettes viewed in white light

$\mathrm{B}$ - the same fragment viewed in UV light of $365 \mathrm{~nm}$

Figure 31. Australia, passport - a travel document, 2008 

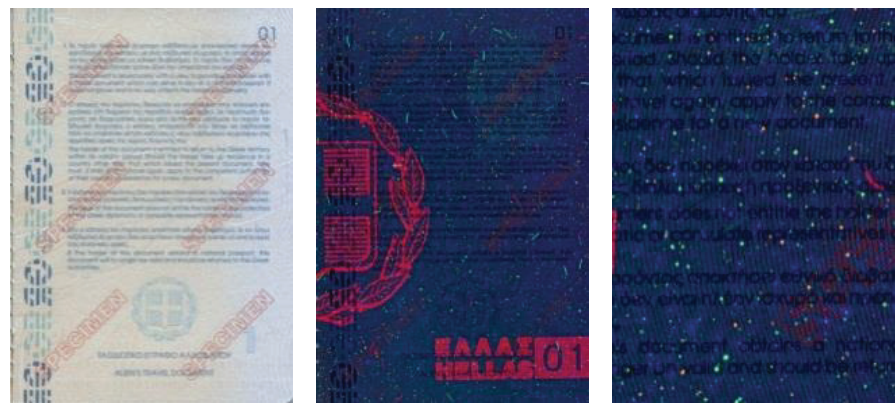

Figure 32. Greece, alien's travel document, view in white light, view in UV light of $365 \mathrm{~nm}$, UV-fluorescent hi-lites

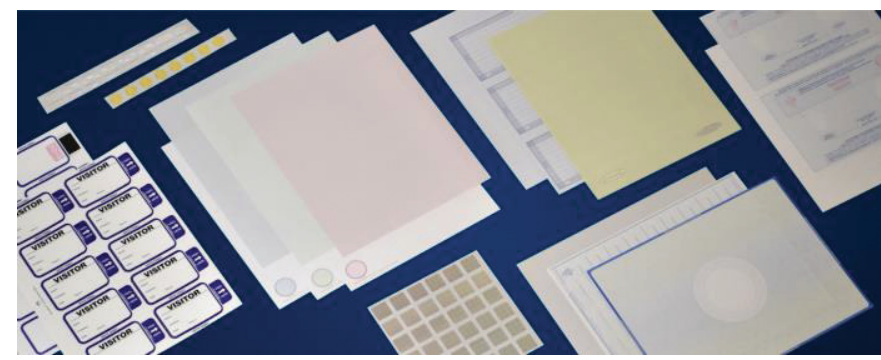

Figure 33. Different types of security paper

\section{List of figures}

Figure 1. Highlight watermark, 1000 Czech Korun (2008); https://regulaforensics.com/ en/knowledge-hub/glossary-banknotes/ (accessed: 9.07.2020).

Figure 2. Pixel watermark, 1000 Kazakh Tenge (2011); https://regulaforensics.com/en/ knowledge-hub/glossary-banknotes/ (accessed: 9.07.2020).

Figure 3. Combined (halftone and highlight), 50 Gibraltar Pounds (2010); https://regulaforensics.com/en/knowledge-hub/glossary-banknotes/.

Figure 4. Great Britain. Passport (2015), multitone shadow local watermark combined with electrotype watermark, https://regulaforensics.com/en/knowledge-hub/glossary-documents/ (accessed: 7.07.2020).

Figure 5. New Zealand, a travel document issued in 2016, dual-tone general watermark; https:// regulaforensics.com/en/knowledge-hub/glossary-documents/ (accessed: 7.07.2020).

Figure 6. Ukraine, refugee's document for traveling abroad issued in 2017, single-tone watermark; https://regulaforensics.com/en/knowledge-hub/glossary-documents/ (accessed: 7.07.2020). 
Figure 7. The Republic of Belarus, diplomatic passport issued in 2010, duotone watermark; https://regulaforensics.com/en/knowledge-hub/glossary-documents/ (accessed: 7.07.2020).

Figure 8. Estonia, a travel document issued in 2013, cornerstone watermark; https:// regulaforensics.com/en/knowledge-hub/glossary-documents/ (accessed: 7.07.2020).

Figure 9. Dandy roll-made watermark; https://coimages.sciencemuseumgroup.org.uk/images/290/432/medium_Y2006_0060_0074_0001_.jpg (accessed: 9.07.2020).

Figure 10. Mould-made watermark; http://www.fabrianosecurity.com/en/21/watermark (accessed: 9.07.2020).

Figure 11. Electrotype made watermark; http://www.fabrianosecurity.com/en/21/watermark (accessed: 9.07.2020).

Figure 12. Dandy roll cylinder; Chahal P.K., Kaur J., Singh P., "Digital watermarking on bank note", International Journal of Soft Computing and Engineering (IJSCE).

Figure 13. Metalized (machine-variable) security thread; Regula Forensics, "Sixty-seven years of passport design and security features: The evolution of the Federal German passport", https://regulaforensics.com/en/pressroom/news/sixty-seven-years-of-passport-design-features-the-evolution-of-the-federal-german-passport/ (accessed: 10.07.2020).

Figure 14. Three types of a security thread; https://www.security-web.nl/glossary-banknotes/\#g648 (accessed: 11.07.2020); http:/www.regulaforensics.com/images/glossary_banknotes (accessed: 10.07.2020).

Figure 15. Metalized security thread; https://www.security-web.nl/glossary-banknotes/\#g648 (accessed: 11.07.2020); http://www.regulaforensics.com/images/glossary_ banknotes (accessed: 10.07.2020).

Figure 16. Semi-transparent with microtext, 10 UAE Dirhams (1982); https://www.security-web.nl/glossary-banknotes/\#g648 (accessed: 11.07.2020); Regula forensics, http://www.regulaforensics.com/images/glossary_banknotes/(accessed: 10.07.2020).

Figure 17. Color changing, 50 Libyan Dinars (2008); https://www.security-web.nl/glossary-banknotes/\#g648 (accessed: 11.07.2020); http:/www.regulaforensics.com/images/glossary_banknotes (accessed: 10.07.2020).

Figure 18. Motion effect, 100000 Lebanese Pounds (2011); https://www.security-web.nl/ glossary-banknotes/\#g648 (accessed: 11.07.2020); http://www.regulaforensics.com/ images/glossary_banknotes/ (accessed: 10.07.2020).

Figure 19. Dark thread without microtext, 20 Dominican Pesos (2009), in a polymer basis; https://www.security-web.nl/glossary-banknotes/\#g648 (accessed: 11.07.2020); http://www.regulaforensics.com/images/glossary_banknotes/(accessed: 10.07.2020).

Figure 20. Poland, passport issued in 2001; https://regulaforensics.com/images/knowledge_hub/glossary_documents (accessed: 11.07.2020).

Figure 21. Sweden, emergency passport issued in 2011; https://regulaforensics.com/images/knowledge_hub/glossary_documents/(accessed: 11.07.2020).

Figure 22. Optically variable effect "scate," 500 Russian Rubles (1997); modification (2010); https://www.security-web.nl/glossary-banknotes/\#g648 (accessed: 11.07.2020); http:// www.regulaforensics.com/images/glossary_banknotes/ (accessed: 10.07.2020). 
Figure 23. Optically variable effect "chameleon," 1000 Russian Rubles (1997), modification 2010; https://www.security-web.nl/glossary-banknotes/\#g648 (accessed: 11.07.2020); http://www.regulaforensics.com/images/glossary_banknotes/ (accessed: 10.07.2020).

Figure 24. Azerbaijan, passport issued in 1998, visible simple monochrome fibers; https:// regulaforensics.com/en/knowledge-hub/glossary-documents/ (accessed: 12.07.2020).

Figure 25. Great Britain, passport issued in 2010; invisible (colorless) simple fibers daylight, and the same under UV light; https://regulaforensics.com/en/knowledge-hub/ glossary-documents/ (accessed: 12.07.2020).

Figure 26. Great Britain, passport issued in 2010, visible (colorless) simple fibers daylight, and the same under UV light; https://regulaforensics.com/en/knowledge-hub/ glossary-documents/ (accessed: 12.07.2020).

Figure 27. Russian Federation, passport issued in 2010, ZONA security fibers, two-colored with a variable cross-section daylight, and the same under UV light; https:// regulaforensics.com/en/knowledge-hub/glossary-documents/ (accessed: 12.07.2020).

Figure 28. UV fluorescent multi-color planchettes, invisible under daylight; https://securitypapers.arjowiggins.com/security/ (accessed: 12.07.2020).

Figure 29. Planchettes, one color; https://securitypapers.arjowiggins.com/security/ (accessed: 12.07.2020).

Figure 30. Visible multi-color planchettes; https://securitypapers.arjowiggins.com/security/ (accessed: 12.07.2020).

Figure 31. Australia, passport - a travel document, 2008; https:/regulaforensics.com/en/ knowledge-hub/glossary-documents/ (accessed: 12.07.2020).

Figure 32. Greece, alien's travel document, view in white light, view in UV light of $365 \mathrm{~nm}, \mathrm{UV}$-fluorescent hi-lites; https://regulaforensics.com/en/knowledge-hub/glossary-documents/ (accessed: 12.07.2020).

Figure 33. Different types of security paper; https://www.highsecuritypaper.com/.

\section{References}

Ahlstrom-Munksjö, "Security fibers used at Ahlstrom-Munksjö to assure greater product traceability", https://www.ahlstrom-munksjo.com/Media/releases/pressreleases2/2018/security-fibers-used-at-ahlstrom-munksjo-to-assure-greater-producttraceability/\#: :text=Security\%20fibers\%20can\%20be\%20used,processed $\% 20$ in $\% 20$ the \%20value\%20chain (accessed: 7.07.2020).

Al Faleh Al Hiary H.A.A., Paper-based watermark extraction with image processing, doctoral thesis, July 2008, http://etheses.whiterose.ac.uk/1355/1/hazem.pdf.

Anjali A., Abhishek A., Uttam S., Priyanka V., "Comparison of various security features of genuine, scanned and photocopied Indian currency note of the denomination 2000", Journal of Forensic Science \& Criminology 5, 2017, no. 3, p. 305.

Baxter J., Special techniques: Embellishments for paper, slideshow, http://www.csus. edu/indiv/c/cunninghamk/links/lectures/5special_process.pdf(accessed: 5.07.2020). 
Centeno A.B., Ramos Terrades O., Lladós Canet J., Cañero Morales C., Identity document and banknote security forensics: A survey, 2019, https://arxiv.org/pdf/1910.08993.pdf.

Chahal P.K., Kaur J., Singh P., "Digital watermarking on bank note”, International Journal of Soft Computing and Engineering (IJSCE) 3, 2014, no. 6.

Chambers J., Yan W., Garhwal A., Kankanhalli M., "Currency security and forensics: A survey”, Multimedia Tools and Applications 74, 2015, no. 11, pp. 4013-4043, https:// doi.org/10.1007/s11042-013-1809-x.

CNBM International Pulp \& Paper, “Cotton pulp making”, http://www.paperpulpingmachine.com/applications/cotton-pulp-making/ (accessed: 19.07.2020).

Cotton Incorporated, "Cotton morphology and chemistry”, https://www.cottoninc.com/ quality-products/nonwovens/cotton-fiber-tech-guide/cotton-morphology-and-chemistry/ (accessed: 19.07.2020).

Cox I.J., Miller M.L., Bloom J.A., Digital watermarking, San Francisco-London 2002.

Deviterne-Lapeyre C.M., "Interpol review of questioned documents 2016-2019”, Forensic Science International: Synergy 2, 2020, pp. 429-441.

Ellen D., Day S., Davies C., Scientific examination of documents: Methods and techniques, Boca Raton, FL 2018.

European Bank for Reconstruction and Development, Sub-sectoral environmental and social guideline: Pulp and paper, 2014. https://www.ebrd.com/documents/environment/env-emanual-manufacture-of-paper-and-paper-products.pdf (accessed: 10.07.2020).

European patent specification, Watermark formation element, International publication number: wo 2016/075442 (19.05.2016 gazette 2016/20), 26.09.2018 bulletin 2018/39, https://patents.google.com/patent/US5766416A/en (accessed: 5.07.2020).

Fabriano Security, "Banknote and security papers", http://www.fabrianosecurity.com/ en/15/banknote_\&_security_papers (accessed: 30.06.2020).

Heij H. de, "Banknote design for retailers and public", DNB Occasional Studies 8, 2010, no. 4, https://www.dnb.nl/binaries/OS0804_tcm46-244782.pdf.

Home Office UK, National Document Fraud Unit, Guidance on examining identity documents, 2016, https://assets.publishing.service.gov.uk/government/uploads/system/ uploads/attachment_data/file/869551/Guidance_on_examining_identity_documentS_v._February_2020.pdf.pdf (accessed: 19.07.2020).

Liu Z., Wang H., Hui L., "Pulping and papermaking of non-wood fibers", [in:] Pulp and paper processing, ed. S.N. Kazi, 2018, IntechOpen, https://www.intechopen.com/ chapters/62223 (accessed: 10.07.2020).

Louisenthal, https://www.louisenthal.com.

Materials analysis in forensic science, ed. M.M. Houck, Amsterdam 2016.

Meggs P.B., A history of graphic design, Chichester 1998, p. 58.

Mini-encyclopedia of papermaking wet-end chemistry: Additives and ingredients, their composition, functions, strategies for use, https://projects.ncsu.edu/project/hubbepaperchem/FIBR.htm (accessed: 18.07.2020).

National Research Council, Counterfeit deterrent features for the next-generation currency design, Washington, D.C. 1993. 
Paper Money Grading (PMG), "Substrate feature: The watermark", 20.08.2013, https:// www.pmgnotes.com/news/article/3525/Substrate-Feature-The-Watermark/ (accessed: 5.07.2020).

Polish Security Printing Works (PWPW), "Security features", https://www.pwpw.pl/en/ Competencies/Security_features.html\#elementy_zabezpieczajace_w_papierze (accessed: 18.07.2020).

Radecepapir Nova, "The watermark: The oldest and most reliable paper protection element", https://www.radecepapir.si/the-watermark-the-oldest-and-most-reliablepaper-protection-element/ (accessed: 5.07.2020).

Regula Forensics, "Glossary of banknotes", https://regulaforensics.com/en/knowledge-hub/glossary-banknotes/ (accessed: 12.07.2020).

Regula Forensics, "Glossary of documents", https://regulaforensics.com/en/knowledge-hub/glossary-documents/ (accessed: 7.07.2020).

Security Paper Mill (SPM), "Security features in paper structure", http://spm.cz/en/ products/security_papers/security_features_in_paper_structure.html (accessed: 7.07.2020).

Shaw M.B., Bicking G.W., "Research on the production of currency paper in the bureau of standards experimental paper mill", Department of Commerce Bureau of Standards, Washington, D.C. 1926.

Thales Group, High-security printing for passport: The 2021 expert's guide, https://www. thalesgroup.com/en/markets/digital-identity-and-security/government/passport/security-printing (accessed: 7.07.2020). 